\title{
A FIELD RESEARCH ON FACTORS AFFECTING BANKING JOB SELECTION
}

\section{DOI: 10.17261/Pressacademia.2018.878 \\ PAP- V.7-2018(31)-p.186-190}

Ismail Atabay ${ }^{1}$, Fatih Karakas², Aysegul Yildirim Kutbay ${ }^{3}$, Bayram Alamur ${ }^{4}$

${ }^{1}$ Balıkesir University, Havran Balıkesir, Turkey.

atabay@balikesir.edu.tr, ORCID: 0000-0001-8979-5548

${ }^{2}$ Balıkesir University, Burhaniye Balıkesir, Turkey.

fatih.karakas@balikesir.edu.tr, ORCID: 0000-0002-7982-8454

${ }^{3}$ Balıkesir University, Burhaniye Balıkesir, Turkey.

aysegulyildirim@balikesir.edu.tr, ORCID: 0000-0002-3100-2928

${ }^{4}$ Balıkesir University, Havran Balıkesir, Turkey.

alamur bayram@hotmail.com , ORCID: 0000-0002-1364-5604

To cite this document

Atabay, I., Karakas, F., Kutbay Yildirim, A., Alamur, B. (2018). A field research on factors affecting banking job selection. PressAcademia Procedia (PAP), V.7, p.186-190.

Permemant link to this document: http://doi.org/10.17261/Pressacademia.2018.878

Copyright: Published by PressAcademia and limited licenced re-use rights only.

\section{ABSTRACT}

Purpose- The purpose of this study is to determine what factors aree ffective in choosing banking department / program for banking students, and whether they differ according to demographic variables.

Methodology- For this purpose, the questionnaire prepared by using the literature has been applied to the students who are studying at thebanking departments / programs of Balıkesir University. The data obtained from the questionnaire were subjected to statistic alanalysis and the results were interpreted.

Findings- In the study, factors affecting job selection were determined in six dimensions. It was determined that the "Gain Assurance and Career" had the highest score and the "Others' Suggestion" had the lowest score from the sub-dimensions of factors affecting the choice of profession of banking education students within the scope of research. It has been determined that the factors affecting the choice of profession differ according to gender and education level.

Conclusion- As a result of the study, it was seen that the most important factor in choosing the profession of the students included in the research is the "Gain Assurance and Career" dimension including the high gain, job finding and career opportunities, job security. As a result of the study, it can be concluded that female students who received banking education gave more importance to their occupational liking and self-esteem in career selection and reputation, status and future importance of the profession than male students. In addition, it can be said that the vocational school banking students give more importance to earnings, assurance and career opportunities while choosing a profession than undergraduate students and they are in the selection due to desperation because they can not go to other alternatives.

Keywords: Job, banking job, job selection.

JEL Codes: G21, 129

\section{BANKACILIK MESLEK SEÇIMINI ETKILEYEN FAKTÖRLERE ILIŞKIN BIR ALAN ARAŞTIRMASI}

\section{ÖZET}

Amaç- Bu çalışma, bankacılık eğitimi alan öğrencilerin bu bölüm/programı seçerken etkili olan faktörlerin neler olduğunu ve demografik değişkenlere göre farklılık gösterip göstermediğini tespit etme amacını taşımaktadır.

Yöntem- Bu amaçla literatürden yararlanılarak oluşturulan anket, Balıkesir Üniversitesinde Bankacılık eğitimi verilen bölüm/programlarda okumakta olan öğrenciler üzerinde uygulanmıştır. Anket çalışmasından elde edilen veriler istatistiksel analizlere tabi tutulmuş ve sonuçlar yorumlanmıştır.

Bulgular- Çalışmada meslek seçimini etkileyen faktörler altı boyutta belirlenmiştir. Araştırma kapsamındaki bankacılık eğitimi alan öğrencilerin meslek seçimini etkileyen faktörlerin alt boyutlarından "Kazanç Güvence ve Kariyer" boyutunun en yüksek skora sahip olduğu, "Başkalarının Önerisi " boyutunun en düşük skora sahip olduğu belirlenmiştir. Meslek seçimini etkileyen faktörlerin cinsiyet ve öğrenim düzeyine göre farklılıklar gösterdiği tespit edilmiştir.

Sonuç- Çalışma sonucunda, araştırma kapsamındaki öğrencilerin meslek seçiminde en önemli faktörün kazanç yüksekliğini, iş bulma ve kariyer olanaklarını, iş güvencesini içeren "Kazanç Güvence ve Kariyer" boyutu olduğu görülmüştür. Çalışma sonucunda bankacılık eğitimi alan kadın öğrencilerin meslek seçiminde mesleği sevme ve kendilerine uygun görme ile mesleğin saygınlık statü ve gelecekteki önemine erkek öğrencilere göre daha fazla önem verdikleri söylenebilir. Ayrıca, bankacılık eğitimi alan ön lisans öğrencilerinin lisans öğrencilerine göre meslek seçiminde kazanç, güvence ve kariyer olanaklarına daha fazla önem verdikleri ve başka alternatiflere yönelemedikleri için çaresizlikten kaynaklanan seçimde bulundukları söylenebilir.

Anahtar Kelimeler: Meslek, bankacılık mesleği, meslek seçimi.

JEL Kodları: G21, 129 


\section{Giriş}

"Meslek" Türk Dil Kurumu tarafından "belli bir eğitim ile kazanılan sistemli bilgi ve becerilere dayalı, insanlara yararlı mal üretmek, hizmet vermek ve karşılığında para kazanmak için yapılan, kuralları belirlenmiş iş" olarak tanımlanmıştır (TDK, 2018). Buna karşın literatürde araştırmacılar tarafından farklı tanımlar yapılmıştır. Kuzgun'un (1994: 51) yaptığı tanıma göre meslek, bireyin yeteneklerini kullanması, kendini geliştirmesi ve gerçekleştirmenin yoludur. Yanıkkerem vd. (2004) ise mesleği; bireylerin yaşamını kazanmak için yaptığı, kuralları toplum tarafından belirlenen ve belirli bir eğitimle kazanılan bilgi, becerilere dayalı etkinlik alanı olarak tanımlamışlardır. Meslek, her ne kadar bireyin hayatını kazanması için yapılan bir faaliyet olarak görülse de, sadece para kazanmak ana amaç olarak görülmemektedir (Kuzgun, 1994: 51; Tuzcuoğlu, 1994: 266). Kazanç, bireylerin meslek seçiminde etkilendikleri en önemli faktör olarak bilinse de, meslek seçimini etkileyen tek faktör değildir. Meslek seçim süreci, bireylerin meslek seçerken kendisine açık meslekleri çeşitli yönleriyle değerlendirip, kendi ihtiyaçlarını dikkate alarak, mesleğin iyi ve iyi olmayan yönlerini değerlendirerek birine yönelmeye karar vermesi sürecidir (Tuzcuoğlu, 1994:265). Meslek seçim süreci bireyin hayatı boyunca yapacağı en önemli seçimlerden biridir. Çünkü bu secim bireyin tüm yaşamını etki etmektedir (Temel, 2006). Meslek seçmek yaşam tarzını seçmek demektir (Yanıkkerem vd., 2004).

Literatür çalışmaları incelendiğinde meslek seçimini etkileyen faktörler ve bu faktörlerin temel alındığı pek çok çalışmaya rastlamak mümkündür. McCabe vd.'nin(2005) çalışmasına göre; hemşirelik bölümü öğrencilerinin meslek tercihindeki etken faktörler insanlara yardımcı olma, işe ilgi duyma, insanlarla yakın ilişki içinde çalışma, iş güvencesi, esnek çalışma saatleri, iş ortamından memnuniyet, heyecan duyma ve maaş olarak sıralanmıştır. Akbayır (2002) tarafından yapılan çalışmada, öğretmenlik mesleğine yönelmede ailenin rolünün etkili olan önemli faktör olduğunu belirlemiştir. Almanya'da Kiel Üniversitesi'nde öğretmenlik eğitimi alan öğrenciler üzerinde yapılan çalışmaya göre; meslek seçimi etkileyen faktörleri eğitim alanına ilgi duyma, öğretmenlik mesleğine ilgi duyma, aileye daha fazla zaman ayırma, finansal boyut, özgüven, zorluk derecesinin az olması ve sosyal etkiler olmak üzere yedi kategoride sınıflandırmıştır (Paulick vd., 2013). Dinç (2008) yaptığı araştırmada, meslek yüksekokulu muhasebe programı öğrencilerinin meslek seçiminde yüksek kazanç, sorumluluk ve kariyer beklentisi, mesleki bilgi ve beceri, mesleki tecrübe ile sosyal statü kazanma arzusundan oluşan beş temel faktörün etkili oluştuğunu, aile çevresi ve eğitim çevresinin ise etkili olmadığı sonucuna ulaşmıştır. Auyeung ve And Sand ( 1997) yaptıkları çalışmada, muhasebe mesleğinin seçimi ile ilgili etmenlerin etkisinin, öğrencilerin kültürel yapılarına göre farklılık gösterdiğini tespit etmişlerdir. Altun (2000) tarafından yapılan çalışmada, üniversitede hemşirelik mesleğini seçen öğrencilerin bu mesleği; iş bulma olanaklarının fazla olması, mesleğe duyulan ilgi, aile ve yakınlarının isteği, puanının düşük olması, mesleğin toplumsal saygınlığının-dürüstlük ve sorumluluk getiren konumda olması, mezun olduğunda parasal getirisinin iyi olması, kişinin meslekte özgür olması, çalışma koşullarının rahatlığı, eğitimin kolay olması gibi nedenlerle seçtikleri tespit edilmiştir. Sarıkaya ve Khorshıd (2009) tarafından üniversite öğrencileri üzerinde yapılan çalışmaya göre; öğrencilerin bir kısmı çaresizlik yaşadığı ve aldığı puanla açıkta kalmaktan korktuğu için, bir kısmı seçtiği mesleğin diğer mesleklere göre avantajları olduğunu düşündüğü için ve diğer bir kısmı da başkalarının önerileri ile mesleği seçtiğini belirtmiştir.

\section{ARAŞTIRMA}

\subsection{Araştırmanın Amacı}

Bu araştırmanın amacı bankacılık eğitimi alan öğrencilerin bu bölüm/programı seçerken etkili olan faktörlerin neler olduğunu ve demografik değişkenlere göre farklılık gösterip göstermediğini tespit etmektir.

\subsection{Araştırmanın Sınırlılıkları}

Bu araştırma Balıkesir Üniversitesine bağı Yüksekokul ve Meslek Yüksekokulları bünyesinde bankacılık eğitimi verilen bölüm/programlarda okuyan öğrenciler üzerinde yapılmış olup, ülkemizin diğer bölgelerindeki farklı üniversitelere bağlı birimler bünyesinde bankacılık eğitimi verilen okullarda okuyan öğrencilerin zaman ve imkanlar nedeniyle araştırmaya dahil edilememiş olması bu araştırmanın kısıtlarını oluşturur.

\subsection{Araştırmanın Örneklemi}

Balıkesir Üniversitesine bağlı Yüksekokul ve Meslek Yüksekokulları bünyesinde bankacılık eğitimi verilen bölüm/programlarda okuyan öğrenciler bu araştırmanın ana kütlesidir. Anket uygulaması için kolayda örnekleme metodu seçilmiş ve uygulama yüz yüze yapılarak gerçekleştirilmiştir. Araştırma kapsamında araştırmaya katılmayı kabul eden 367 öğrenci ile görüşülmüştür. Eksik bilgi verilen 11 anket araştırmaya dahil edilmeyerek, 356 anket veri analizinde kullanılmıştır.

\subsection{Araştırmada Kullanılan Veri Toplama Araçları ve Verilerin Analizi}

Araştırmada, veri toplama aracı olarak anket yöntemi kullanılmıştır. Anket formu, öğrencilerin meslek seçimini etkileyen faktörlerin belirlenmesi amacıyla yapılmış çalışmalardan yararlanılarak oluşturulmuştur. Anket formu iki kısımdan oluşmaktadır. Birinci kısım sosyodemografik bilgiler, ikinci kısım meslek seçimini etkileyen faktörler ile ilgilidir. İkinci kısımda meslek seçimini etkileyen faktörlerle ilgili 29 önermeye yer verilmiş ve öğrencilerden bu önermeleri (1) Kesinlikle Katılmıyorum , (2) Kısmen Katılmıyorum, (3) Emin Değilim, (4) Kısmen Katılıyorum, (5) Kesinlikle Katılıyorum olmak üzere 5'li likert ölçeğine göre cevaplandırmaları istenmiştir. Verilerin analizinde SPSS 22 istatistik paket programı kullanılmıştır.

\section{ARAŞTIRMA BULGULARI VE VERILERIN ANALIZi}

\subsection{Demografik Faktörlere İlişkin Bulgular}

Aşağıdaki Tablo 1'de ankete katılan öğrencilerin demografik özelliklerini gösteren frekans dağılımları görülmektedir. 
Tablo 1: Cevaplayıcıların Demografik Özelliklerine iliş̧kin Değerler

\begin{tabular}{|c|c|c|c|c|c|c|c|c|}
\hline Cinsiyet & Frekans & Yüzde & Sınıfı & Frekans & Yüzde & Mezun Olunan Lise & Frekans & Yüzde \\
\hline $\begin{array}{l}\text { Kadın } \\
\text { Erkek }\end{array}$ & $\begin{array}{l}234 \\
122\end{array}$ & $\begin{array}{l}65,7 \\
34,3\end{array}$ & $\begin{array}{l}\text { 1.Sinif } \\
\text { 2.Sinif }\end{array}$ & $\begin{array}{r}137 \\
90\end{array}$ & $\begin{array}{l}38,5 \\
25,3\end{array}$ & $\begin{array}{l}\text { Düz Lise/Anadolu Lisesi } \\
\text { Ticaret Meslek Lisesi }\end{array}$ & $\begin{array}{r}182 \\
38\end{array}$ & $\begin{array}{l}51,1 \\
10,7\end{array}$ \\
\hline Toplam & 356 & 100,0 & 3.Sinıf & 62 & 17,4 & Diğer Meslek Lisesi/Kız Meslek Lisesi & 122 & 34,3 \\
\hline Yaș & Frekans & Yüzde & 4.Sinıf & 67 & 18,8 & Diğer & 14 & 3,9 \\
\hline 18 ve Altı & 24 & 6,7 & Toplam & 356 & 100,0 & Toplam & 356 & 100,0 \\
\hline $19-21$ & 241 & 67,7 & Öğrenim Düzeyi & Frekans & Yüzde & & & \\
\hline $\begin{array}{l}22-24 \\
25-27\end{array}$ & $\begin{array}{r}86 \\
1\end{array}$ & $\begin{array}{r}24,2 \\
, 3\end{array}$ & $\begin{array}{l}\text { Ön Lisans } \\
\text { Lisans }\end{array}$ & $\begin{array}{r}99 \\
257\end{array}$ & $\begin{array}{l}27,8 \\
72,2\end{array}$ & & & \\
\hline 28 ve Üstü & 4 & 1,1 & Toplam & 356 & 100,0 & & & \\
\hline Toplam & 356 & 100,0 & & & & & & \\
\hline
\end{tabular}

\subsection{Faktör Analizi, Güvenilirlik Testi ve Diğer Analizler}

Meslek seçimini etkileyen faktörlere ilişkin olarak yapılan faktör analizinin ve güvenilirlik testlerinin sonuçları Tablo-2'de yer almaktadır. Yapılan açıklayıcı faktör analizi sonucunda, 29 ifadeden oluşan meslek seçimini etkileyen faktörler ölçeğinden, ölçek yapısını bozan 3 soru çıkarılmış ve 6 faktör elde edilmiştir.

Tablo 2: Meslek Seçimini Etkileyen Faktörlere İlişkin Açıklayıcı Faktör ve Güvenilirlik Analizi Sonuçları

\begin{tabular}{|c|c|c|}
\hline Faktörler & Faktör Yükü & Cronbach's Alpha \\
\hline \multicolumn{3}{|l|}{ Faktör-1 Mesleğin Sevilmesi ve Uygunluk (MSU) } \\
\hline Mesleği sevdiğim için seçtim. & ,874 & \multirow{6}{*}{,898 } \\
\hline Yaşam tarzına uygun bir meslek olduğu için seçtim. &, 847 & \\
\hline İlgi duyduğum bir meslek olduğu için seçtim. &, 846 & \\
\hline Bu mesleğe yeteneğim olduğunu düşündüğüm için seçtim. & 827 & \\
\hline Kişisel özelliklerime uygun olduğunu düşündüğüm için seçtim. & ,774 & \\
\hline Cinsiyetime uygun olduğu için seçtim. & 677 & \\
\hline \multicolumn{3}{|l|}{ Faktör-2 Meslek Elastikiyeti (ME) } \\
\hline Sorumluluk almayı gerektiren bir meslek olduğu için seçtim. & ,893 & \multirow{4}{*}{,850 } \\
\hline Disiplinli ve düzenli çalışmayı gerektiren bir meslek olduğu için seçtim. &, 825 & \\
\hline Güven esasına dayalı bir meslek olduğu için seçtim. & ,813 & \\
\hline Hareketli ve dinamik bir meslek olduğu için seçtim. & ,680 & \\
\hline \multicolumn{3}{|l|}{ Faktör-3 Başkalarının Önerisi (BO) } \\
\hline Akrabalarımın tavsiyesi/yönlendirmesi ile seçtim. &, 864 & \multirow{5}{*}{,785 } \\
\hline Arkadaşlarımın tavsiyesi/yönlendirmesi ile seçtim. 8 & ,744 & \\
\hline Ailemin tavsiyesi/yönlendirmesi ile seçtim. & ,712 & \\
\hline Öğretmenlerimin tavsiyesi/yönlendirmesi ile seçtim. & ,667 & \\
\hline Bu işi yapan bir tanıdığımın etkisi ile seçtim. & ,662 & \\
\hline \multicolumn{3}{|l|}{ Faktör-4 Kazanç, Güvence ve Kariyer (KGK) } \\
\hline İş bulma olanağının yüksek olması nedeniyle seçtim. & 859 & \multirow{4}{*}{,818 } \\
\hline İş güvencesinin yüksek olduğu bir meslek oluşu nedeniyle seçtim. & ,840 & \\
\hline Meslekte ilerleme ve kariyer imkanları olduğu için seçtim. & ,769 & \\
\hline Kazancı yüksek bir meslek olduğu için seçtim. & ,697 & \\
\hline \multicolumn{3}{|l|}{ Faktör-5 Saygınlık, Statü ve Gelecek (SSG) } \\
\hline Toplumda saygınlığı olan bir meslek olduğu için seçtim. & ,881 & \multirow{3}{*}{,886 } \\
\hline Belirli bir sosyal statüye sahip insanların tercih ettiği bir meslek olduğu için seçtim. & ,868 & \\
\hline Gelecekte geçerliliğini koruyacak bir meslek olduğu için seçtim. & ,859 & \\
\hline \multicolumn{3}{|l|}{ Faktör-6 Çaresizlik (CR) } \\
\hline Lisedeki meslek eğitimimin devamı oluşu nedeniyle seçtim. & ,781 & \multirow{4}{*}{,706 } \\
\hline Üniversite giriş sınav puanım bu bölüme yettiği için seçtim. & ,726 & \\
\hline Eğitiminin basit ve kolay olduğunu düşündüğüm için seçtim. & ,700 & \\
\hline Ailemle yaşadığım yerde olması/yakın olması nedeniyle seçtim. & ,675 & \\
\hline \multicolumn{3}{|l|}{$\begin{array}{l}\text { Çıkarım Metodu: Principal Component Analysis. } \\
\text { Döndürme Metodu: VarimaxwithKaiserNormalization }\end{array}$} \\
\hline \multicolumn{3}{|l|}{ Keiser-Meyer-OlkinMeasure of SamplingAdequacy : ,809 } \\
\hline Açıklanan toplam varyans: 65,371 & & \\
\hline Toplam Cronbach's Alpha :, 787 & & \\
\hline
\end{tabular}

Yapılan faktör analizi sonucunda, ölçeğin 6 boyuttan oluştuğu görülmektedir. Bu boyutlar, ifadelerin içerikleri dikkate alınarak, "Mesleğin Sevilmesi ve Uygunluk (MSU)", "Meslek Elastikiyeti (ME)”, "Başkalarının Önerisi (BO)”, "Kazanç, Güvence ve Kariyer (KGK)”, "Saygınlık, Statü ve Gelecek (SSG)" ve "Çaresizlik (CR)" olarak isimlendirilmiştir. Ölçeğin boyutlarının güvenirliliğini belirlemek için her boyut için alfa katsayısı hesaplanmıştır. Boyutların alfa katsayılarının 0,70'ın üstünde olması yeterli derecede güvenirlilik koşulunun karşılandığını göstermektedir (İslamoğlu ve Alnıaçık, 2016). Özdeğeri 1'den büyük olan faktörler dikkate alınmıştır. Ölçeğin açıklanan toplam varyans değeri 65,371 olarak, toplam Cronbach's Alpha değeri ise 0,787 belirlenmiştir. 
Ölçeğin geçerlilik ve güvenilirliği sağlandıktan sonra, meslek seçimini etkileyen faktörlerin alt boyutları arasındaki korelasyon ve bazı tanımlayıcı istatistikleri incelemek yerinde olacaktır. Bu amaçla aşağıdaki Tablo-4 hazırlanmışır.

Tablo 4: Meslek Seçimini Etkileyen Faktörlerin Alt Boyutları Arasındaki Korelasyonlar ve Bazı Tanımlayıcı İstatistikler

\begin{tabular}{lllllll}
$\mathbf{( 1 )}$ & $\mathbf{( 2 )}$ & $\mathbf{( 3 )}$ & $\mathbf{( 4 )}$ & $\mathbf{( 5 )}$ & Ortalama & Std.Sapma \\
\hline & & & & & 3,0530 & 1,10545 \\
, $219^{* *}$ & & & & & 3,2584 & 1,10820 \\
, 047 &, 037 & & & & 2,2074 & 1,01468 \\
, $119^{*}$ &, $303^{* *}$ &, 043 & & & 3,3868 &, 96354 \\
, $293^{* *}$ &, $336^{* *}$ &,- 025 &, $115^{*}$ & & 3,2959 & 1,12748 \\
,- 083 &,$- 126^{*}$ &, $153^{* *}$ &, 101 &,$- 172^{* *}$ & 2,4459 &, 98173
\end{tabular}

** $p<0.01 * p<0.05$

Analiz sonuçlarına göre; meslek seçimini etkileyen faktörler alt boyutlarından "Mesleğin Sevilmesi ve Uygunluk (MSU)" ile "Meslek Elastikiyeti (ME)" ve "Saygınlık, Statü ve Gelecek (SSG)" arasında $\mathrm{p}<0.01$ anlamlılık düzeyinde, "Kazanç, Güvence ve Kariyer (KGK)" arasında ise $p<0.05$ anlamlılık düzeyinde pozitif ilişki elde edilmiştir. Meslek seçimini etkileyen faktörler alt boyutlarından "Meslek Elastikiyeti (ME)" ile "Kazanç, Güvence ve Kariyer (KGK)" ve "Saygınlık, Statü ve Gelecek (SSG)" arasında p <0.01 anlamlılık düzeyinde pozitif, "Çaresizlik (CR)" arasında ise $p<0.05$ anlamlıık düzeyinde negatif ilişki elde edilmiştir. Meslek seçimini etkileyen faktörler alt boyutlarından "Başkalarının Önerisi (BO)" ile "Çaresizlik (CR)" arasında p <0.01 anlamlılık düzeyinde pozitif ilişki elde edilmiştir. Meslek seçimini etkileyen faktörler alt boyutlarından "Kazanç, Güvence ve Kariyer (KGK)" ile "Saygınlık, Statü ve Gelecek (SSG)" "p <0.05 anlamlılık düzeyinde pozitif ilişki elde edilmiştir. Meslek seçimini etkileyen faktörler alt boyutlarından "Saygınlık, Statü ve Gelecek (SSG)" ile "Çaresizlik (CR)" arasında ise $p<0.01$ anlamlıık düzeyinde negatif ilişki elde edilmiştir.Tabloda yer alan sonuçlara göre anket kapsamındaki bankacılık eğitimi alan öğrencilerin meslek seçimini etkileyen faktörlerin alt boyutlarından "Kazanç Güvence ve Kariyer (KGK)" boyutunun en yüksek skora sahip olduğu, "Başkalarının Önerisi (BO)" boyutunun ise en düşük skora sahip olduğu anlaşılmaktadır.

Ankete katılan bankacılık eğitimi alan öğrencilerin meslek seçimini etkileyen faktörlere ait alt boyutlarının puanlarının cinsiyet değişkenine göre karşılaştııılmasına ilişkin yapılan T-Testi sonuçları Tablo 5'de verilmiştir.

Tablo 5: Cinsiyet Değişkenine Göre T-Testi Sonuçları

\begin{tabular}{llllllll}
\hline CINSIYET & & MSU & ME & BO & KGK & SSG & CR \\
\hline \multirow{3}{*}{ KADIN } & Ortalama & 3,2088 & 3,2799 & 2,1686 & 3,3919 & 3,4573 & 2,4637 \\
& $\mathbf{N}$ & 234 & 234 & 234 & 234 & 234 & 234 \\
& Std. Sapma & 1,10057 & 1,14864 & 1,00832 &, 94872 & 1,11320 & 1,01346 \\
\hline \multirow{2}{*}{ ERKEK } & Ortalama & 2,7541 & 3,2172 & 2,2820 & 3,3770 & 2,9863 & 2,4119 \\
& $\mathbf{N}$ & 122 & 122 & 122 & 122 & 122 & 122 \\
& Std. Sapma & 1,05631 & 1,02950 & 1,02683 &, 99526 & 1,09377 &, 92090 \\
\hline $\mathbf{t}$ & & 3,751 &, 506 & $-1,001$ &, 138 & 3,811 &, 472 \\
\hline $\mathbf{d f}$ & & 354 & 354 & 354 & 354 & 354 & 354 \\
\hline $\mathbf{p}$ & $\mathbf{0 0 0 * *}$ &, 613 &, 318 &, 891 &, $\mathbf{0 0 0 * *}$ &, 637 \\
\hline & & $* * p<0,01$ & & & & &
\end{tabular}

Ankete katılan bankacııık eğitimi alan öğrencilerin meslek seçimini etkileyen faktörlere ait alt boyutlarını puanlarının öğrenim düzeyi değişkenine göre karşılaştııılmasına ilişkin yapılan T-Testi sonuçları Tablo 6'da verilmiştir.

Tablo 6: Öğrenim Düzeyi Değişkenine Göre Karşılaştırılmasına ilişşkin T-Testi Sonuçları

\begin{tabular}{llllllll}
\hline ÖĞRENIM DÜZEYi & & MSU & ME & BO & KGK & SSG & CR \\
\hline ÖN LiSANS & Ortalama & 2,6418 & 3,1793 & 2,1980 & 3,6455 & 3,1111 & 2,9091 \\
& $\mathbf{N}$ & 99 & 99 & 99 & 99 & 99 & 99 \\
& Std. Sapma & 1,12537 & 1,27977 & 1,09162 & 1,01562 & 1,34434 & 1,06991 \\
\hline LiSANS & Ortalama & 3,2114 & 3,2889 & 2,2111 & 3,2872 & 3,3671 & 2,2675 \\
& $\mathbf{N}$ & 257 & 257 & 257 & 257 & 257 & 257 \\
& $\mathbf{S t d . ~ S a p m a ~}$ & 1,05792 & 1,03571 &, 98566 &, 92561 & 1,02600 &, 88509 \\
\hline $\mathbf{t}$ & & 4,472 &, 762 &, 109 & $-3,184$ & 1,712 & $-5,771$ \\
\hline $\mathbf{d f}$ & & 354 & 150,033 & 354 & 354 & 144,134 & 354 \\
\hline $\mathbf{p}$ & & $\mathbf{3 0 0 * *}$ &, 448 &, 913 & $\mathbf{0 0 2 * *}$ &, 089 & $\mathbf{0 0 0 * *}$ \\
\hline$* * p<0,01$ & & & & & &
\end{tabular}




\section{SONUÇ}

Bu çalışmada Balıkesir Üniversitesine bağlı Yüksekokul ve Meslek Yüksekokulları bünyesinde bankacılık eğitimi verilen bölüm/programlarda okuyan öğrencilerin bu bölüm/programı seçiminde etkili olan faktörlerin neler olduğu ve demografik değişkenlere göre farklılık gösterip göstermediği incelenmiştir.

Araştırma sonuçlarına göre anket kapsamındaki bankacılık eğitimi alan öğrencilerin meslek seçimini etkileyen faktörlerin alt boyutlarından "Kazanç Güvence ve Kariyer (KGK)" boyutunun puanının 3,3868 olduğu ve en yüksek skora sahip olduğu, "Başkalarının Önerisi (BO)" boyutunun puanının ise 2,2074 olduğu ve en düşük skora sahip olduğu anlaşılmaktadır. Buna göre anket kapsamındaki öğrencilerin meslek seçiminde en önemli faktörün kazanç yüksekliğini, iş bulma ve kariyer olanaklarını, iş güvencesini içeren "Kazanç Güvence ve Kariyer (KGK)" boyutu olduğu söylenebilir.

Araştırmada, anket kapsamındaki bankacılık eğitimi alan öğrencilerin meslek seçimini etkileyen faktörlerin cinsiyet değişkenine göre bazı farklılıklar gösterdiği görülmüştür. Meslek seçimini etkileyen faktörlerin alt boyutlarından “Mesleğin Sevilmesi ve Uygunluk (MSU)” puanının kadınlarda 3,2088 erkeklerde ise 2,7541 olduğu, "Saygınlık, Statü ve Gelecek (SSG)" puanın da kadınlarda 3,4573 erkeklerde ise 2,9863 olduğu ve p>0,01 önem düzeyinde istatistiksel anlamda farklılık gösterdiği görülmektedir. Meslek seçimini etkileyen faktörlere ait diğer alt boyutlarda ise kadın ve erkekler arasında istatistiksel olarak anlamlı bir farklılık tespit edilmemiştir. Bu durumda bankacılık eğitimi alan kadın öğrencilerin meslek seçiminde mesleği sevme ve kendilerine uygun görme ile mesleğin saygınlık statü ve gelecekteki önemine erkek öğrencilere göre daha fazla önem verdikleri söylenebilir.

Araştırmada, anket kapsamındaki bankacılık eğitimi alan öğrencilerin meslek seçimini etkileyen faktörlerin öğrenim düzeyi değişkenine göre de bazı farklılıklar gösterdiği görülmüştür. Meslek seçimini etkileyen faktörlerin alt boyutlarından "Mesleğin Sevilmesi ve Uygunluk (MSU)" puanının ön lisans eğitimi alan öğrencilerde 2,6418 olduğu, lisans eğitimi alan öğrencilerde ise 3,2114 olduğu ve p>0,01 önem düzeyinde istatistiksel anlamda farklılık gösterdiği görülmektedir. Buna göre, bankacılık eğitimi alan lisans öğrencilerinin ön lisans öğrencilerine göre meslek seçiminde mesleği sevmelerinin ve kendilerine uygun görmelerinin daha önemli olduğu söylenebilir. Meslek seçimini etkileyen faktörlerin alt boyutlarından "Kazanç, Güvence ve Kariyer (KGK)" puanının ön lisans eğitimi alan öğrencilerde 3,6455 olduğu, lisans eğitimi alan öğrencilerde ise 3,2872 olduğu, "Çaresizlik (CR)" puanının ön lisans eğitimi alan öğrencilerde 2,9091 olduğu, lisans eğitimi alan öğrencilerde ise 2,2675 olduğu ve p>0,01 önem düzeyinde istatistiksel anlamda farklılık gösterdiği görülmektedir. Buna göre, bankacılık eğitimi alan ön lisans öğrencilerinin lisans öğrencilerine göre meslek seçiminde kazanç, güvence ve kariyer olanaklarına daha fazla önem verdikleri ve başka alternatiflere yönelemedikleri için çaresizlikten kaynaklanan seçimde bulundukları söylenebilir.

Araștırmamız Balıkesir Üniversitesine bağlı Yüksekokul ve Meslek Yüksekokulları bünyesinde bankacılık eğitimi verilen bölüm/programlarda okuyan öğrenciler üzerinde yapılmış olup, diğer üniversitelerde öğrenim görmekte olan bankacılık eğitimi verilen bölüm/programlarda okuyan öğrenciler üzerinde ve/veya üniversitelerin farklı mesleklere yönelik bölüm/programlarında okuyan öğrenciler üzerinde de benzer araştırmaların yapılması gelecekteki araştırmacılara önerilmektedir.

\section{KAYNAKÇA}

Akbayır, K. (2002). Öğretmenlik mesleğine yönelmede ailenin ve branş seçiminde cinsiyetin rolü. V. Ulusal Fen Bilimleri ve Matematik Eğitimi Kongresi Dergisi, 2, 1183-1188.

Altun, İ. (2000). Kocaeli Sağlık Yüksekokulu öğrencilerinin kişisel değerleri ve meslek seçimlerine etki eden faktörler. I. Uluslararası \& VIII. Ulusal Hemşirelik Kongresi Kitabı, 75- 77.

Auyeung, P., Sand, J. (1997). Factors influencing accounting students' career choice: a cross-cultural validation study. Accounting Education: An International Journal, 6(1), 13-23.

Dinç, E. (2008). Meslek seçiminde etkili faktörlerin incelenmesi: meslek yüksekokulu muhasebe programı öğrencileri üzerine bir Araştırma. Kocaeli Üniversitesi Sosyal Bilimler Enstitüsü Dergis, 16 (2), 90-106.

İslamoğlu, A. H., Alnıaçık, Ü. (2016). Sosyal bilimlerde araştırma yöntemleri. Genişletilmiş 5. Baskı, Beta Yayınevi.

Kuzgun, Y. (1994). Çağdaş insanın en önemli kararı meslek seçimi. Bilim ve Teknik.

McCabe, R., Nowak, M., Mullen, S. (2005). Nursing careers: what motivated nurses to choose their profession? Australian Bulletin of Labour, 31(4), 384-406.

Paulick, I., Retelsdorf, J., Möller, J. (2013). Motivation for choosing teacher education: Associations with teachers' achievement goals and instructional practices. International Journal of Educational Research, 61, 60-70.

Sarıkaya, T., Khorshıd, L. (2009). Üniversite öğrencilerinin meslek seçimini etkileyen etmenlerin incelenmesi: üniversite öğrencilerinin meslek seçimi. Türk Eğitim Bilimleri Dergisi, 7(2), 393-423.

Temel, A. (2006). Alan ve meslek seçiminde dikkat edilmesi gereken hususlar. Milli Eğitim Dergisi, 1, 1-11.

TDK (2018). Genel Türkçe sözlük. Türk Dil Kurumu, http://www.tdk.gov.tr/index.php?option=com_gts , (Erişim Tarihi: 12.05.2018).

Tuzcuoğlu, S. (1994). Meslek Seçimi ve Önemi Eğitim Bilimleri Dergisi. M.Ü. Atatürk Eğitim Fakültesi, 6, 265-280.

Yanıkkerem, E., Altınparmak, S., Karadeniz , G. (2004). Gençlerin meslek seçimini etkileyen faktörler ve benlik Saygıları. Nursing Forum Dergisi, 7(2), 61-62. 